\title{
Uma Perspectiva Neoconstitucional da Regulação do Espectro Radioelétrico
}

\section{Guilherme Pereira Pinheiro}

Doutorando em Direito pela Universidade de Brasília UnB. Mestre em Direito Comparado pela Columbia University Law School em Nova York - LL.M. Mestre em Direito e Políticas Públicas pelo Centro Universitário de Brasília - Uniceub. MBA em Gestão de Empresas pela Fundação Getúlio Vargas FGV. Especialização em Direito da Regulação e da Concorrência pelo Uniceub. Professor de Direito Regulatório em curso de Especialização em Direito Público do Cead-UnB e de Direito Civil no Instituto de Ensino Superior de Brasília - lesb. Advogado, trabalha no setor de telecomunicações desde 2001. guilherme@spcomm.com.br

\section{Resumo}

Este artigo tem o objetivo de deslindar o conteúdo jurídico do espectro radioelétrico e, a partir daí, avaliar a possibilidade, pertinência e as consequências da aplicação de uma análise neoconstitucionalista à regulação do espectro. 0 estudo focará quais os efeitos da incidência dessa análise sobre três espécies de direitos fundamentais, quais sejam, direito à informação, direito à educação e a vedação ao monopólio e oligopólio dos meios de comunicação. 0 artigo conclui pela possibilidade de aplicação da análise neoconstitucional sobre a regulação do espectro e serve como guia a orientar futuras instrumentalizações das garantias jurídicas referentes aos direitos fundamentais que possam incidir sobre essa regulação.

Palavras-chave: Neoconstitucionalismo. Regulação. Espectro radioelétrico. Direitos fundamentais. 


\title{
A NEOCONSTITUTIONAL PERSPECTIVE ON RADIO SPECTRUM REGULATION
}

\begin{abstract}
This article intends to identify the legal contents of the radioelectric spectrum and, from this starting point, to assess the possibility, adequacy and consequences of applying a neoconstitutional analisys to its regulation. The study will focus these effects over the following fundamental rights: the right to information, the right to education and the nonmonopoly rights on communications. The article concludes for the possibility and desirability of the neoconstitutional approach to spectrum regulation and serves as a guide in orienting future actions to enforce fundamental constitutional rights related to radio spectrum.
\end{abstract}

Keywords: Neoconstitutionalism. Regulation. Radioelectric spectrum. Fundamental rights.

\section{Sumário}

1 Considerações Iniciais. e suas falhas e limitações. 20 espectro radioelétrico e sua regulação. 2.1 A importância do tema. 2.2 Um conceito jurídico do espectro radioelétrico. 2.30 estágio da atual regulação do espectro e suas falhas. 3 Neoconstitucionalismo. 3.10 que é neoconstitucionalismo. 3.2 Possíveis impactos do neoconstitucionalismo na regulação do espectro radioelétrico. 3.3 Elementos para uma nova regulação do espectro sob a perspectiva neoconstitucional. 3.3.1 0 direito à informação. 3.3.2 0 direito à educação. 3.3.3. Vedação ao monopólio ou oligopólio dos meios de comunicação. 3.4 Parâmetros Materiais e Formais para a Efetividade dos Direitos Fundamentais Ligados à Regulação do Espectro. 4 Conclusão. 5 Referências 


\section{CONSIDERAÇÕES INICIAIS}

Este texto tem o objetivo de esmiuçar o conceito jurídico de espectro radioelétrico e levantar as hipóteses de como a perspectiva neoconstitucionalista (Barroso, 2007) pode ser aplicada a alguns direitos relacionados à regulação do espectro. ${ }^{1}$ Com esse intuito, abordaremos três direitos atinentes à regulação do espectro: (i) o direito à informação, constante do inciso XIV do artigo $5^{\circ}$ do texto constitucional; (ii) o direito social à educação, estampado no artigo $6^{0}$ do mesmo texto; e (iii) a vedação ao monopólio ou oligopólio dos meios de comunicação, presente no $\S 5^{\circ}$ do artigo 220 da Constituição Federal

Diante disso, numa primeira parte, intentaremos, em primeiro lugar, mostrar resumidamente a importância do espectro para as telecomunicações e suas múltiplas ramificações. Em seguida esboçaremos um conceito jurídico de espectro radioelétrico, abarcando sua natureza jurídica e buscando extrair daí a consequente relação jurídico-regulatória entre o Estado e o bem público do espectro radioelétrico. Na sequência, procuraremos expor o atual estágio regulatório do espectro e suas falhas e limitações.

Na segunda parte, procuraremos, no primeiro item, conceituar neoconstitucionalismo para, logo após, discorrermos acerca dos impactos do neoconstitucionalismo na regulação do espectro radioelétrico, em especial no que diz respeito ao direito à informação, ao direito à educação e à vedação ao monopólio ou oligopólio dos meios de comunicação.

${ }_{1}$ Luís Roberto Barroso explica que o chamado neoconstitucionalismo nasceu da confluência de três grandes transformações, quais sejam: a) o reconhecimento de força normativa à Constituição; b) a expansão da jurisdição constitucional; c) o desenvolvimento de uma nova dogmática da interpretação constitucional. A seguir, a análise sucinta de cada uma delas. Vide: Barroso, Luís Roberto. Neoconstitucionalismo e constitucionalização do Direito. O triunfo tardio do Direito Constitucional no Brasil. In: Revista Eletrônica sobre a Reforma do Estado, Salvador, n. ${ }^{9}$, MAR/ABR/MAI, 2007, p. 1-41. 


\section{ESPECTRO RADIOELÉTRICO E SUA REGULAÇÃO}

\subsection{A importância do tema}

A qualidade, a pluralidade de fontes e o potencial de acesso à informação eletrônica são três termômetros essenciais de uma sociedade democrática. De fato, a consciência de uma determinada comunidade deriva dos conhecimentos e tradições auferidos nos valores culturais e sociais dessa sociedade (Brenton; Proulx, 1996, p. 92). Hoje, e em tendência cada vez mais crescente, os meios de comunicação e as fontes de informação são digitalizados e o acesso a essas fontes é condição imperativa para a integração de cada pessoa nessa sociedade.

Há, por exemplo, trabalhos recentes que tentam quantificar os impactos econômicos de um importante aspecto no uso do espectro: sua aplicação na telefonia móvel. Um grupo de economistas (Waverman, 2011) estimou que acréscimos na penetração de serviços de telefonia móvel em países em desenvolvimento foram acompanhados de consideráveis incrementos no Produto Interno Bruto - PIB desses países. O referido estudo descobriu que nos países onde ocorreu uma variação de $10 \%$ nos níveis de penetração da telefonia móvel houve uma correspondente diferença, em média, de 0,6\% no PIB anual em relação ao países em que não aconteceu essa penetração.

Um estudo do Banco Mundial também estabeleceu a íntima relação entre comunicações móveis (que utilizam o espectro radioelétrico) e o crescimento econômico. Esse estudo, que ocorreu entre 1980 e 2006 (Qiang, 2009, p. 35-50), concluiu que, nos países em desenvolvimento, um aumento de $10 \%$ na penetração de telefonia móvel corresponde a um aumento de $0,6 \%$ no PIB per capita (o que é consistente com o estudo de Waverman citado anteriormente) e em um aumento de $0,8 \%$ do PIB per capita de países em desenvolvimento. E isso apenas para telefonia móvel, 
sem contar os prováveis impactos econômicos advindos do aumento da penetração da banda larga móvel e de outros serviços de informação e telecomunicações que fazem uso do espectro radioelétrico.

No âmbito de uma sociedade da informação, ${ }^{2}$ o poder converge para quem controla a informação. A liberdade equitativa de oportunidades pressupõe uma uniformidade maior de base intelectual para seu exercício (Rawls, 2003, p. 56). Para Marcos Alberto Bitelli (2004, p. 190), o direito à comunicação social é o direito de difundir, sob algumas reservas, o exercício das prerrogativas fundamentais do inciso IX, artigo $5^{\circ}$, da Constituição Federal. ${ }^{3}$ Esse direito de comunicação social seria resultado da liberdade de manifestação do pensamento que consta do inciso IV desse mesmo artigo $5^{\circ}$ de nossa Carta Magna. E o espectro radioelétrico é o bem público mais eficiente para concretizar esses direitos, em especial num país com as condições econômicas e da extensão geográfica do Brasil.

\subsection{Um conceito jurídico do espectro radioelétrico}

Antes de analisarmos o espectro sob a ótica jurídica, é oportuno apreendermos seu conceito do ponto de vista técnico, bem como alguns dos elementos econômicos a ele afetos.

Do ponto de vista da Engenharia, numa acepção puramente técnica, o espectro radioelétrico ou de radiofrequências é uma expressão empregada descrever bandas de frequências eletromagnéticas, que se estendem de aproximadamente $10 \mathrm{KHz}$ a $300 \mathrm{GHz}$. Essas bandas são divididas em

2 Não existe um conceito uno de sociedade da informação. O conceito utilizado neste trabalho é o mesmo utilizado por Manuel Castells em seu The Rise of the Network Society: The Information Age: Society, Economy and Culture.

3 Artigo 5 $5^{\circ}$, IX - É livre a expressão da atividade intelectual, artística científica e de comunicação, independentemente de censura ou licença. 
partes distintas, que são usadas para diversas aplicações, como telefonia celular, acesso a banda larga sem fio, distribuição de sinais de TV por satélite, e assim por diante.

Hoje, no Brasil, estão alocadas radiofrequências para os mais diversos serviços de telecomunicações, como o serviço de telefonia móvel (serviço móvel pessoal), o serviço de comunicação multimídia (SCM), serviço de TV por assinatura por satélites (DTH), destinações para uso exclusivo das Forças Armadas, entre outros ${ }^{4}$. Algumas emissões de radiofrequência, consideradas de radiação restrita, geralmente de baixa potência, são deixadas ao livre uso das pessoas. É o caso de alarmes de carros, controles de portão de garagens, walk-talkies, etc.

No campo econômico, podemos destacar que o principal valor do espectro está em sua capacidade de transportar os mais diferentes tipos de informação, nas mais variadas velocidades e nas mais diferentes distâncias (Levin, 1971, p. 15). Os aspectos econômicos mais proeminentes ligados ao espectro radioelétrico são, dentre outros, os seguintes: (i) escassez; (ii) existência de barreiras à entrada; (iii) rivalidade por interferência prejudicial; (iv) o aspecto renovável do espectro que pode ser usado repetidamente sem desgaste; (v) existência de maior oferta de equipamentos em determinadas faixas e serviços; (vi) existência de efeitos de economia de redes ou efeitos de rede (network effects). Como outros recursos naturais, o espectro está condicionado às variáveis de oferta e demanda.

4 Para mais detalhes na atribuição de faixas de radiofrequências, vide: $<$ http://www.anatel. gov.br/Portal/verificaDocumentos/documento.asp?numeroPublicacao=98580\&assunto Publicacao=Quadro\%20de\%20Atribuição\%20\&caminhoRel=Cidadao-Radiofreqüência-Atribuição,\%20Destinação\%20e\%20Distribuição\%20de\%20Faixas\&filtro=1\&documentoPath=ra diofrequencia/qaff.pdf>. Acesso em: 17 ago. 2011. 
Vemos, portanto, que as políticas que orientam a utilização do espectro e a filosofia e os pressupostos inseridos em sua regulação têm muita importância numa sociedade que podemos chamar de Sociedade da Informação.

Do ponto de vista jurídico, o espectro constitui um bem público. É essa ao menos a definição contida na Lei Geral de Telecomunicações - LGT ${ }^{5}$ - que dispõe ainda que o espectro é um bem limitado e que este será administrado pela Agência Nacional de Telecomunicações - Anatel. O inciso XXI do artigo $4^{\underline{0}}$ da Resolução n. ${ }^{\circ}$ 259/2001/Anatel define o espectro de radiofrequências como "o bem público, de fruição limitada, cujo uso é administrado pela Agência, que corresponde a uma parte do espectro eletromagnético abaixo de $3.000 \mathrm{GHz}$, que se propaga no espaço sem guia artificial e que é, do ponto de vista do conhecimento tecnológico atual, passível de uso por sistemas de radiocomunicação.”6

Não obstante a concisão das definições dadas anteriormente, elas muitas vezes não correspondem à manifestação jurídica do que é de fato o espectro radioelétrico. Senão vejamos. O espectro é definido como bem público, mas qual bem público e por quê? Seria um bem móvel ou imóvel? Imaterial ou material? Um bem escasso, mas não exaurível? Na verdade o conceito de espectro é uma abstração jurídica. O espectro não existe por si só, concretamente na natureza. Ele passa a existir quando alguém

\footnotetext{
5 Artigo 157 da Lei n. ${ }^{\circ}$ 9.472/1997.

6 Importante notar que, tecnicamente, a expressão espectro radioelétrico refere-se à espécie do espectro que se estende até os $3.000 \mathrm{GHz}$ (espécie do gênero espectro eletromagnético). Já a expressão espectro eletromagnético refere-se ao gênero, abrangendo toda a amplitude do espectro.
} 
procede a uma operação que aplica energia a uma antena e daí é emitido um sinal codificado que é entregue e decodificado em outra antena. Se nenhum sinal é emitido, não há que se falar em espectro. ${ }^{7}$

Tarefa árdua também é tentar cotejar o espectro com outros institutos jurídicos, o que, em vez de jogar luz sobre o tema, pode tornar mais nebuloso o trabalho do estudioso do Direito. Tomemos o exemplo do potencial de energia hidráulica. ${ }^{8}$ Poderíamos tentar compará-lo ao espectro. Ocorre que o potencial de energia hidráulica é um bem que existe concretamente na natureza, como um rio, uma cachoeira, uma corrente de água. Nesse caso o potencial, que é uma coisa material, concreta, pertence ao Estado. Já o “espectro" que pertence ao Estado é o direito de emitir a onda eletromagnética, não o espaço físico em que as ondas transitam nem o espectro abstratamente considerado. Até porque o espectro é uma construção teórica, uma abstração matemática e suas bandas e canais constituem uma convenção cifrada para os entendermos. O bem do Estado é o direito de emitir sinais. Assim entende Gaspar Ariño et al, para quem "lo que es un bien es el derecho al uso de las frecuencias pero non el espacio ni tampoco el espectro considerados en sí mismos".

7 Nesse sentido: nadie puede apropiarse de las ondas, sencillamente por que non existen al menos hasta que alguien aplica energía a una antena de determinada forma. El espectro radioeléctrico es una abstracción matemática y sus bandas e canales una convención cifrada para entendernos. Ver em: Ariño, Gaspar, et al.. Las Telecomunicaciones por Cable. Su Reguilación presente y futura. Madrid: Pere-Marcial Pons., 1996. p. 386.

8 Quando falamos de potencial de energia hidráulica não podemos deixar de mencionar os artigos 118 e 119 da Constituição de 1934, uma dissociação entre a água e seu potencial hidráulico, o que foi visto como algo quase revolucionário na época. Tais normas, como explica Luiz Gustavo Kaercher Loureiro, foram vistas “como aberrantes pela doutrina mais liberal, justamente por favorecer o incremento do controle da indústria elétrica mediante a instituição de propriedade pública de sua fonte primordial, qual seja, dos potenciais de energia. Vide em: Loureiro, Luiz Gustavo. Constituição energia e setor elétrico. Porto Alegre: Ed. Fabris Editor, 2009. p. 42.

9 Loureiro, Luiz Gustavo. Constituição, energia e setor elétrico, 2009. p. 387. 
É preciso admitir que não existe um conceito jurídico fechado de espectro e que este conceito tem mais a ver com o uso jurídico do espectro do que com aquilo que, concreta e materialmente, constitui esse espectro. Diante disso podemos assegurar que mais do que um bem, no sentido jurídico, o espectro radioelétrico revela-se um conjunto de direitos relacionados às atividades que utilizam o espectro. Isso em nada retira ou reduz a competência ou capacidade de o Estado disciplinar ou regular as atividades relacionadas ao uso do espectro radioelétrico. Esta é também a visão de alguns autores, como Marcos M. Fernando Pablo (2004, p. 704), Yonchai Benkler (2002), Yves Gaudemet e André Chaminade,,$^{10}$ entre outros.

Como conjunto de potencialidades que têm o condão de produzir reflexos no mundo concreto, dado o preenchimento de algumas condições, o espectro radioelétrico pode ser entendido com bem jurídico? Alguns juristas, como Yves Gaudemet, entendem que sim. Historicamente, o reconhecimento de um bem como público foi o que primeiro deitou as bases e premissas para uma regulação das respectivas atividades que utilizam esses bens, bem como o entendimento de que certos bens devem alcançar a realização de determinados fins comuns. Cretella Jr. lembra que a ação popular nasceu dessa pré-condição finalística dos bens públicos (1984, p. 10). Essa finalidade de realizar determinados fins coletivos, no entanto, pode estar tanto no bem público quanto nos bens comuns.

Os bens públicos podem ser divididos em res publicae ou em res comunis omnium. Como res publicae, o espectro seria um bem público propriamente dito, de propriedade do Estado e por ele disciplinado e regulado. No sentido romano de res communis omnium, o espectro seria um bem pertencente a todos, a toda a coletividade (Kiss, 1985, p. 423-441).

${ }^{10}$ Gaudemet, Yves; Chaminade, André. Le Système Français D’Exploitation du Domaine Public Hertizien et D’Attribuition des Fréquences Radioelétriques. 2006. Disponível em: $<$ http://www.fondation-droitcontinental.org/upload/docs/application/pdf/2011-10/rapport_mai_2010.pdf . Acesso em: 2 maio 2013. 
Bens pertencentes à noção de res communis omnium não são bens sem dono, res nullius, e portanto não podem ser apropriados nem utilizados de forma contrária ao interesse coletivo. A consideração do espectro como uma res publicae ou como uma res communis omnium teria sérias consequências para o enquadramento jurídico do espectro, bem como para a relações derivadas das noções de neoconstitucionalismo que veremos adiante. No primeiro caso, seria permitida uma maior regulação e intervenção do Estado, enquanto no segundo, embora pressuponha a manutenção do interesse público, abrir-se-ia menos espaço para a atuação estatal.

Sob o prisma constitucional, a Constituição de 1988 não traz o espectro expressamente no rol dos bens públicos. O inciso I do artigo 20 da Carta Constitucional, porém, dispõe que são de propriedade da União os bens que "atualmente lhe pertencem e os que lhe vierem a ser atribuídos”. Dessa forma, a favor da posição de que o espectro constitui uma res publicae, pode-se argumentar que: (i) o espectro radioelétrico já pertencia à União quando da promulgação da Constituição de 1988; ou que (ii) uma nova lei atribuísse a propriedade do espectro à União após a promulgação da Constituição de 1988. O caso parece mesmo ser o da segunda hipótese, com o artigo 157 da LGT, que caracteriza o espectro como bem público.

Antes de encerrar esse item, contudo, analisemos as posições distintas de dois autores sobre o assunto. Primeiro Yves Gaudemet que, apesar de admitir a possibilidade de o espectro vir a ser entendido como uma res communis omnium, entende que no estágio atual é melhor que se empreste uma interpretação no sentido de que o espectro seja tratado como res publicae (Gaudemet, Chaminade, 2006). Para este jurista, as vantagens de se ter um domínio público sobre o espectro são: (i) afetação das frequências a sua utilidade pública; (ii) submissão das frequências a um regime de proteção da dominialidade pública; (iii) aplicação dos 
princípios da inalienabilidade e imprescritibilidade; (iv) a percepção de receitas pelo Estado decorrentes do uso do espectro e (v) a submissão a uma autorização administrativa.

Por outro lado, temos José Carlos Laguna de Paz, que aduz que a maior parte das vantagens apontadas pelos defensores do enquadramento do espectro como bem público poderiam ser asseguradas sem que fosse necessário um modelo dominial público. Este autor destaca, ainda, que a qualificação do espectro radioelétrico como domínio público, além de não ser a ideal, pode ser prejudicial, pois: (i) há uma debilitação da posição jurídica dos operadores que pretendem usar o espectro, uma vez que este pode sofrer restrições regulatórias a qualquer momento; (ii) não se pode falar em comercialização do espectro, pois os bens dominiais são res extracomercium, mas sim de transferência de títulos administrativos habilitantes.

Independentemente das visões expostas anteriormente, e relevando algumas imprecisões e incongruências jurídicas apontadas, é seguro aduzir que, no atual panorama brasileiro o espectro pode ser entendido com um bem público, imaterial, escasso e administrado pela Anatel.

\subsection{0 estágio da atual regulação do espectro e suas falhas}

Desde a publicação da LGT, que reestruturou o setor de telecomunicações brasileiro, a utilização do espectro radioelétrico passou a ser disciplinada exclusivamente pela Anatel. De acordo com a LGT, o uso da radiofrequência é outorgado pela Anatel, em forma de autorização. Ocorre que a radiofrequência é geralmente utilizada na prestação de serviços públicos, o que requereria a outorga de concessão ou permissão, ao menos nos termos da Lei n. .0 8.987/1995. 
De fato, Marçal Justen Filho aduz que havendo serviço público não seria o caso de autorização (2003, p. 45). A autorização contida na LGT, no entanto, tem natureza jurídica mais próxima da concessão. E isso porque a maioria dos serviços que utilizam o espectro de radiofrequência são serviços de interesse coletivo, de natureza pública. Serviços de interesse coletivo são aqueles que são "objeto de oferta comercial dirigida ao público em geral, devendo sua prestação ser proporcionada pela prestadora a qualquer interessado na sua fruição, em condições não discriminatórias” (Xavier, 2003, p. 37). Vemos, portanto, que a autorização para uso do espectro é dada para serviços públicos que visam ao atendimento do público em geral.

Assim é, na visão de Floriano Peixoto Azevedo Marques, pois “a exploração do serviço autorizado, embora tratado como mera exploração de atividade econômica em sentido estrito, necessita do uso de um bem público como condição" para a prestação do serviço. Outro exemplo desse uso da nomenclatura autorização no lugar de concessão está no aproveitamento de potencial hidráulico de determinada energia. ${ }^{11}$

No plano regulatório, o modelo brasileiro de regulação do espectro pode ser enquadrado, de acordo com a literatura estrangeira, como um modelo chamado de command and control. Este modelo significa que o poder público fraciona o espectro em partes de frequência e aloca determinados serviços a essas frações do espectro. Se houver necessidade, por escassez, há uma licitação para a destinação de determinada faixa a determinada empresa.

Benjamin (2002) apresenta uma série de desvantagens trazidas pelo modelo de regulação command and control. A maior delas seria um panorama de frequências não utilizadas ou utilizadas de forma ineficiente. É um modelo rígido que não permite que um espectro de radiofrequência

${ }^{11}$ Vide artigo $7^{\circ}$, II, da Lei n. 9.074/1995. 
subutilizado seja empregado para outra finalidade. O autor argumenta também que se os prestadores de serviço estão impedidos de usar a frequência para fins mais eficientes, existirá um incentivo ao desperdício do espectro, que, como vimos, é um bem público.

Por fim, Benjamin explica que a permissão para que haja apenas a prestação de um serviço por fração do espectro impede que empresas e pesquisadores desenvolvam novos serviços e tecnologias naquela faixa do espectro. A falta de flexibilidade desestimula a otimização de novas soluções, restringe as opções de alternativas que tem o órgão regulador e pode, inclusive, resultar na concentração do espectro nas mãos de empresas e grupos que se acomodam perigosamente no uso de um bem público (2002, p. 69).

A título de ilustração, Martin Cave, Chris Doyle e William Webb apresentam quatro exemplos específicos das falhas do modelo command control de regulação do espectro. O primeiro trata da alocação de espectro para serviços que ficaram sem utilização durante mais de uma década, como o do telefone in-flight ou da última geração dos serviços de paging. O segundo exemplo são as enormes variações de preço entre leilões com larguras de bandas de espectro semelhantes, o que deixa entrever uma “eleição" de bandas vencedoras e perdedoras pelo regulador. O terceiro exemplo são as dificuldades encontradas por novos aplicativos ou tecnologias para terem acesso ao espectro, como aconteceu com os sistemas de TV móvel até pouco tempo atrás. Isso pode inibir o desenvolvimento de novas tecnologias. Por último, algumas aplicações que utilizam espectro gratuitamente, como radares de aviação, não modernizaram seus sistemas durante décadas, o que sugere que inexistem incentivos suficientes para que alguns setores otimizem o uso do espectro (Cave et al., 2007). 
De uma forma geral, podemos induzir que o modelo atual, por ser dotado de maior rigidez, pressupõe uma antecipação das tendências tecnológicas pelo regulador, o que se revela tarefa extremamente dificultosa num mercado em que a tecnologia e o status de desenvolvimento avançam com celeridade imprevisível.

O objetivo do presente estudo não é adentrar nos detalhes dos problemas advindos do atual modelo regulatório do espectro radioelétrico no Brasil. O que pretendemos, com os parágrafos anteriores, foi apenas levantar alguns de seus aspectos mais gerais e direcionar o leitor a algumas fontes bibliográficas para o aprofundamento do assunto. Esses e outros problemas, no entanto, estão na raiz da abertura para a possibilidade de utilização de ferramentas neoconstitucionais na regulação do espectro, que busquem a efetivação de direitos fundamentais ligados ao espectro. É o que veremos no próximo item.

\section{NEOCONSTITUCIONALISMO}

\subsection{0 que é neoconstitucionalismo}

Neoconstitucionalismo é o termo utilizado para designar uma série de mudanças pelas quais tem passado o Direito brasileiro a partir da Constituição de 1988 e que envolve vários fenômenos reciprocamente relacionados: (i) reconhecimento da força normativa da Constituição; (ii) rejeição ao formalismo e adesão a estilos mais abertos de raciocínio jurídico; (iii) constitucionalização do Direito: irradiação das normas e valores constitucionais para todos os ramos do ordenamento jurídico; (iv) reaproximação entre Direito e moral; (v) judicialização da política e das relações sociais, com um deslocamento de poder da esfera do Legislativo para o Executivo (Sarmento, 2009, p. 113). 
No Brasil, o neoconstitucionalismo deve muito ao que se chama de doutrina brasileira da efetividade, ${ }^{12}$ bem como às teorias pós-positivistas, que trouxeram à discussão autores que estudam a relação entre Direito e moral, como John Rawls, Jürgen Habermas, Ronald Dworkin, e dos estudos da hermenêutica jurídica que procurou corrigir os equívocos da interpretação assentada unicamente na separação entre sujeito, intérprete, e o objeto, ou seja, o texto da norma (Streck, 2011, p. 117).

O neoconstitucionalismo tem também um viés interpretativo, que deriva da verificação de que os problemas deixaram de ser apenas o conjunto de fatos sobre o qual incidirá a norma, mas se transformaram em parte na fonte de elementos jurídicos que formarão o Direito. Esse remapeamento do que é problema e do que é a norma decorre dos mais variados fatores, tanto de uma compreensão mais precisa de fenômenos que sempre existiram quanto do reconhecimento de uma maior complexidade da vida moderna, composto por múltiplos e "válidos projetos existenciais e visões de mundo" (Barroso, 2009, p. 309).

No que respeita ao Direito Administrativo, objeto próprio deste artigo, tem-se um cenário no qual houve a combinação: (i) da existência de uma vasta quantidade de normas constitucionais que tratam da administração pública; (ii) do conjunto de alterações sofridas pelo Estado brasileiro recentemente, especialmente nos anos do governo Fernando Henrique Cardoso e (iii) de uma crescente influência dos princípios constitucionais sobre institutos do Direito Administrativo. Isso tudo contribuiu

${ }^{12}$ Luís Roberto Barroso explica que efetividade significa a realização do Direito, o desempenho concreto de sua função social... (representa) a materialidade, no mundo dos fatos, dos preceitos legais e simboliza a aproximação, tão íntima quanto possível, entre o ser normativo e o ser da realidade social. Barroso, Luís Roberto. A doutrina brasileira da efetividade. Temas de Direito Constitucional. Tomo III. Rio de Janeiro: Renovar, 2005, p. 71. 
para o fenômeno, assim como em outros ramos do Direito, como o Direito Civil, de uma constitucionalização do Direito Administrativo (Barroso, 2009, p. 101).

Luís Roberto Barroso exemplifica essa influência com o caso da redefinição da ideia de supremacia do interesse público sobre o interesse privado, em que primário seria o interesse da sociedade traduzido em seus anseios de justiça e bem-estar social, e secundário, no qual estaria o interesse da pessoa jurídica de direito público propriamente dita. Ou seja, diante de uma perspectiva neoconstitucional, nem sempre tais espécies de interesses seriam coincidentes. Com isso, haveria uma vinculação da administração à Constituição e não somente à lei (Barroso, 2009, p. 103-104).

\subsection{Possíveis impactos do neoconstitucionalismo na regulação do espectro radioelétrico}

Neste item procuraremos estabelecer um liame entre a regulação do espectro radioelétrico e o fenômeno neoconstitucionalista. Classificamos o espectro como bem público.

No item 1.1 mencionamos que o espectro constitui um bem público, no entanto, mais que bem público, no sentido limitativo de uma res publicae, podemos considerar o espectro como pertencente ao domínio público. Domínio público não deve se confundir com patrimônio administrativo. Ruy Cirne Lima aduz que "o conceito de domínio público e de patrimônio administrativo excede ao de propriedade pública”. Nesse sentido, continua o mencionado autor, "podemos dizer ... que formam o domínio público e o patrimônio administrativo, todos os bens, pertençam a quem pertencerem, que participam da atividade administrativa e se achem, por isso mesmo vinculados ao fim dela”. Cirne Lima conclui afirmando que a tese de Otto Mayer, de que o domínio público implica propriedade pública, foi 
superada e derrotada pela tese de Léon Duguit, para quem a propriedade pública não é elemento necessário ao conceito de domínio público (Lima, 2007, p. 186).

Essa desvinculação do bem jurídico do espectro da noção de propriedade pública parece encaixar-se com maior perfeição ao cenário delineado pelo neoconstitucionalismo atual, principalmente no que se refere à questão dos direitos constitucionais subjetivos. Barroso preceitua que as "normas constitucionais definidoras de direitos investem os seus beneficiários em situações jurídicas imediatamente desfrutáveis”, que devem ser efetivadas por prestações positivas ou negativas pelo Estado ou por outra pessoa descrita na norma (Barroso, 2005, p. 74). Daí que, para a doutrina da efetividade, de onde bebe o fenômeno neoconstitucional, uma vez que todas as normas constitucionais são dotadas de eficácia e instituidoras de comandos imperativos, os direitos subjetivos, sejam eles políticos, individuais, sociais ou difusos, podem ser exigidos do Estado por meio do direito de ação. Esse direito de ação pode ser materializado mediante ações constitucionais e infraconstitucionais, que constituem a garantia da efetivação dos direitos subjetivos. Tudo isso se aplica ao espectro radioelétrico.

Vale destacar que o rol de direitos fundamentais do artigo $5^{\circ}$ da Constituição Federal não é exaustivo. ${ }^{13}$ Para que um direito seja fundamental e enseje, portanto, a direta proteção constitucional, é necessário que tais direitos sejam revestidos de um conjunto de propriedades gerais e abstratas que o tornem fundamental. Bernal Pulido argumenta que tais características podem ser condensadas em duas espécies: as propriedades formais e as propriedades materiais. As propriedades formais são, alter-

${ }^{13}$ Dispõe o $\S 2^{\circ}$ do artigo $5^{\circ}$ da Carta Constitucional que "os direitos e garantias expressos nesta Constituição não excluem outros decorrentes do regime e dos princípios por ela adotados, ou dos tratados internacionais em que a República Federativa do Brasil seja parte”. 
nada ou cumulativamente: (i) pertencer ao capítulo dos direitos fundamentais da Constituição; (ii) fazer parte do texto constitucional lato sensu; (iii) fazer parte do chamado bloco constitucional e/ou (iv) que a jurisdição lhe reconheça a validade do caráter fundamental. Quantos aos aspectos materiais que caracterizam um direito como fundamental, Bernal Pulido destaca a inclusão: (i) dos interesses fundamentais da pessoa liberal, que contempla o rol de liberdades negativas; (ii) os interesses fundamentais da pessoa democrática, como a possibilidade de participação social e política na vida em sociedade; (iii) as necessidades básicas da pessoa no Estado Social, que encerra o princípio da solidariedade (Bernal Pulido, 2010).

Com isso, na hipótese de aplicarmos um viés neoconstitucionalista na regulação do espectro, devemos sempre atentar para que os direitos identificados sejam de fato direitos fundamentais garantidos constitucionalmente.

Tendo tal premissa em mente, passamos a analisar, a seguir, sob a ótica do discurso neoconstitucional, cada um dos três direitos atinentes ao espectro a que nos propusemos no início deste artigo, quais sejam: (i) o direito à informação, constante do inciso XIV do artigo $5^{0}$ do texto constitucional; (ii) o direito à educação, constate do artigo $6^{\circ}$ do texto constitucional, e (iii) a vedação ao monopólio ou oligopólio dos meios de comunicação, presente no $\S 5^{\circ}$ do artigo 220 da Constituição Federal.

\subsection{Elementos para uma nova regulação do espectro sob a perspectiva neoconstitucional}

\subsubsection{O direito à informação}

$\mathrm{O}$ direito à informação constante do inciso XIV do artigo $5^{\circ}$ do texto constitucional não se limita simplesmente ao "enfoque do conceito de informação jornalística direto, relacionado à liberdade de imprensa, ou ainda ao direito de informação no plano institucional” (Bitelli, 2004). O direito à 
informação ${ }^{14}$ pode ser definido como o direito que todo ser humano tem de obter "informações ou conhecimentos para satisfazer às suas necessidades de saber, compreender as faculdades de buscar ou procurar informações, o que equivale a afirmar que a pessoa pode estar informada tanto por ter pesquisado quanto por lhe ter sido dada a informação” (Silva, 1997).

O problema é que, nos dias atuais, o direito à informação é mais perfeitamente concretizado por meio do acesso direto a meios eletrônicos de comunicação, seja para ler uma notícia em jornais e estar apto a exercer com plenitude e consciência de causa direitos políticos, ou para se informar do que lhe seja pessoalmente de interesse. Para tanto, alguns países têm tornado o acesso à Internet por banda larga um direito fundamental. É o caso da Finlândia. Uma pesquisa conduzida pela rede inglesa BBC conclui que cerca de $80 \%$ das pessoas concorda que o acesso à Internet deveria ser considerado um direito fundamental. ${ }^{15}$

Entendemos, com isso, que o direito à comunicação social é mais que um mero direito de manifestação do pensamento sob diversas formas. O direito à comunicação social consiste, outrossim, na consolidação do direito à informação, que é o

\footnotetext{
${ }^{14}$ Quando usamos a expressão "direito à informação” não podemos deixar de recorrer ao paralelo do "direito à saúde”. Como explica Gustavo Amaral, a expressão "direito à saúde" é equivocado, pois constituiria quase uma demanda ante o Criador, que nos fez limitados e sujeitos à morte. $\mathrm{O}$ que seria apropriado, de acordo com o autor, é usar a nomenclatura direito a cuidados de saúde. Vide: Amaral, Gustavo. Saúde Direito de Todos, Saúde Direito de Cada Um: Reflexões para a Transição da Práxis Jurídica. In: Nobre, Milton; Da Silva, Ricardo (Coords.). CNJ e os Desafios da Efetivação do Direito à Saúde. Belo Horizonte: Fórum, 2011, p. 81 . O mesmo acontece em maior ou menor grau quando falamos em direito à informação. Ao menos no que toca ao espectro radioelétrico, o que queremos defender é um direito de acesso potencial, por meio do espectro, a informações disponíveis em meio eletrônico, e não o direito de que as pessoas leiam ou tenham acesso a uma mesma "informação".

${ }^{15}$ Veja em: <http://www.bbc.co.uk/news/10461048>. Acesso em: 22 ago. 2012.
} 
direito de toda a sociedade em ser bem informada, de forma ampla e diversa, de modo a propiciar, livre e isonomicamente, a formação e consciência política, social e cultural dos indivíduos, garantindo a todos o acesso aos meios de comunicação de massa para que possam receber e transmitir pensamentos e opiniões, com vistas a assegurar também o pluralismo político e social definidores de uma sociedade democrática (Lopes, 1997).

Ou seja, o direito de acesso à comunicação social eletrônica, mais do que o simples direito de ter um canal para se manifestar é o direito de ser informado ou de ter acesso à informação de domínio público e de se educar. É a maneira de se integrar a uma determinada sociedade.

Diante disso, e sob o viés neoconstitucionalista, a concretização do direito subjetivo à informação passa, numa sociedade da informação, pelo acesso democrático aos meios necessários e adequados para tal finalidade. Nesse sentido, seria possível, por exemplo, que um cidadão questionasse uma decisão da Anatel que: (i) deixasse de alocar espectro radioelétrico suficiente para atender à demanda de uma determinada região por informação eletrônica, incluindo, nesse caso, acesso a serviços de TV por assinatura com tecnologia sem fio, acesso wireless à Internet por banda larga, etc.; (ii) elevasse desproporcional e não razoavelmente os custos de determinados serviços de acesso à banda larga; (iii) que criasse uma regulamentação que inibisse ou obstaculizasse a expansão da infraestrutura de redes sem fio que utilizam o espectro.

\subsubsection{O direito à educação}

O direito fundamental à educação consta do caput do artigo $6^{\circ}$ do texto constitucional. Nesse caso, o uso social do espectro teria utilidade para garantir uma equidade de disputa intelectual e de formação entre as pessoas num dado mercado de trabalho. Seria uma contribuição aos 
dois princípios fundamentais de justiça de que nos fala Rawls: a igualdade equitativa de oportunidades e o valor equitativo de liberdades políticas iguais (Rawls, 2003).

A era da cibercultura abre uma perspectiva diferente na relação entre homem e conhecimento, que deixa de ser predominantemente hierárquica e passa a ser mais horizontal e compartilhada (Dias, 1999). Diante dessa nova dinâmica, o leitor passa a interagir cada vez mais com a redação e a edição do documento estudado, algo que era impensado fora dos círculos acadêmicos há cerca de duas décadas. Pierre Lévy considera que, por meio da utilização do hipertexto, toda leitura torna-se uma escrita potencial (Lévy, 1993).

Podemos inferir que a comunicação social eletrônica tem relação íntima com a educação, em dois níveis principais. Primeiro aquele que se refere ao modo como a própria prática pedagógica está sendo modificada como resultado do avanço dos meios de comunicação eletrônica, ou seja, uma prática mais interativa e menos contemplativa, resultado direto da utilização de mecanismos de comunicação eletrônica no ensino. No segundo ponto temos a questão do incremento substantivo no volume de informação circulante e das ferramentas de manipulação dessas informações, que foram potencializadas pelos novos meios de comunicação e precisam ser absorvidas pelos estudantes e professores.

Assim sendo, assumindo uma perspectiva neoconstitucional no uso do espectro em questões ligadas à educação podemos vislumbrar a possibilidade de ações judiciais que, visando à concretude do direito fundamental à educação, obriguem o Estado: (i) a prover a disponibilização, seja por meio de licitação, seja por meio de concessões temporárias de uso, uma parcela do espectro para que entidades de educação (escolas, universidades, etc.) que o solicitem e possam dele fazer bom uso como ferramenta educacional; (ii) elaborar regulamentação que contemple obrigações de provedores de serviços de telecomunicações que façam uso do espectro 
e cujos conteúdos sejam instrumentos úteis para a educação, que ofertem esses serviços a preços e condições vantajosas para instituições de ensino; (iii) a criar mecanismos regulatórios que incentivem e facilitem o acesso a conteúdos educacionais na Internet, por meio da banda larga.

De sua natureza jurídica de bem público, e mais que isso, de domínio público, ao menos uma parcela do espectro deve ser desocupada e disposta livremente em prol da consecução do direito fundamental à educação.

\subsubsection{Vedação ao monopólio ou oligopólio dos meios de comunicação}

Analisemos, por fim, o disposto no $\S 5^{\circ}$ do artigo 220 da Constituição Federal, que veda a organização de oligopólios e monopólios sobre os meios de comunicação social. Classicamente, no que se refere ao uso do espectro radioelétrico, esses meios englobam os serviços de radiodifusão sonora, o rádio, e o de radiodifusão de sons e imagens, a televisão aberta.

André de Godoy Fernandes, em brilhante tese de Doutorado, mostra que a concentração na mídia pode ser: (i) vertical, englobando as diferentes cadeias de valor de uma indústria de comunicação, como as atividades de produção, de empacotamento e de distribuição de conteúdo eletrônico; (ii) horizontal, quando se dá entre empresas ou entidades situadas na mesma posição na cadeia produtiva, resultando numa concentração entre potenciais concorrentes; (iii) uma concentração multimídia, também chamada de propriedade cruzada, que consiste numa concentração em que uma mesma empresa possui o controle de diferentes tipos de veículos de comunicação, como rádios, canais de TV, TVs por assinatura ou provedores de acesso à Internet em uma mesma localidade ou região e (iv) uma concentração multissetorial, que se consubstancia na formação de 
conglomerados de mídia, em que uma pessoa, empresa ou grupo exerce atividades em setores econômicos distintos, representando a diversificação da participação financeira nos mais variados mercados. ${ }^{16}$

Cada uma dessas espécies de concentração pode atentar contra a vedação constitucional expressa em relação à formação de monopólios ou oligopólios nos meios de comunicação. A Constituição de 1988 trouxe significativa proteção às empresas de radiodifusão, pelo poder histórico do setor em razão do sucesso da penetração dos vários lobbies de grandes setores da mídia, e de entidades estatais e paraestatais, o que teria resultado numa Constituição chapa-branca, onde cada setor, estatal ou privado com influência política relevante, detém suas próprias normas de proteção e atuação (Sundfeld, 2008, p.15

De qualquer forma, quando estivermos diante de uma tal situação de formação de monopólio ou oligopólio dos meios de comunicação social que fazem uso do espectro radioelétrico, são possíveis ações que: (i) exijam da Anatel e do Conselho Administrativo de Defesa Econômica - Cade - que abram procedimento administrativo para investigar e, se for o caso, intervir nas estruturas societárias das empresas no sentido de remover ou reduzir a concentração dos meios de comunicação social. Tais ações visariam, por exemplo, a forçar a venda ou o fracionamento de empresas ou de atividades específicas realizadas por essas empresas; (ii) exigir que o poder público e o Congresso Nacional, nos processos de renovação das concessões, permissões e autorizações para a prestação dos serviços que contemplem o uso do bem público do espectro, levem em consideração os aspectos relacionados à concentração dos meios de comunicação.

${ }_{16}$ Para maior aprofundamento acerca deste assunto, recomendamos a leitura da Tese de Doutorado de André de Godoy Fernandes, intitulada Meios de Comunicação Social no Brasil: Promoção do Pluralismo, Direito Concorrencial e Regulação - USP, 2009. 


\subsection{Parâmetros Materiais e Formais para a Efetividade dos Direitos Fundamentais Ligados à Regulação do Espectro}

Como mencionamos en passant, e deixam claro vários autores, como Ana Paula Barcellos (2006), Gustavo Binenbojm (2001), etc., a transposição de uma teoria da efetividade para uma efetividade de fato não ocorre sem problemas. Com essa preocupação em mente, e sem pretender esgotar o assunto em tão curto espaço, podemos subscrever os ensinamentos de Cláudio Pereira Souza Neto, que propõe alguns parâmetros para a atividade judicializante na consubstanciação de direitos fundamentais atinentes ao espectro.

Nesse sentido, dentro do que Souza Neto denomina de parâmetros materiais, temos de verificar se há realmente uma materialidade para que a atuação judicial seja legítima. Essa materialidade refere-se às "condições necessárias para que cada um possua igual possibilidade de realizar um projeto razoável de vida” (Souza Neto, 2008, p. 535). Além disso, a atuação do Judiciário deve restringir-se aos hipossuficientes. No caso do espectro, entendemos que essa restrição aplica-se à hipótese da efetivação dos direitos à informação e à educação.

Souza Neto lembra, ainda, que deve haver a possibilidade de universalização da medida para todos os hipossuficientes. Se o Judiciário concedesse pedidos apenas para parcela dos hipossuficientes haveria violação ao princípio da igualdade. Dessa forma, os "direitos sociais só são judicialmente exigíveis quando a prestação requerida for passível de universalização entre os que não podem arcar com seus custos com recursos próprios" (2008, p. 541).

Ademais, é necessário que seja dada prioridade para as opções mais técnicas da administração pública, quando, por exemplo, houver limitações excessivas em determinadas faixas do espectro radioelétrico. Por fim, também dentro dos parâmetros materiais, há a recomendação de se dar prioridade para a solução mais econômica e de que haja uma propor- 
cionalidade entre a intensidade do controle jurisdicional e os níveis de investimento de determinada política pública. Em outras palavras, se a administração "investe consistentemente em políticas públicas, o Judiciário deve ser menos incisivo" (Souza Neto, 2008, p. 543). Por outro lado, se esses investimentos são escassos ou raramente realizados o Judiciário deve desempenhar um papel mais intenso.

Finalmente, no que diz respeito aos parâmetros formais para a atuação equilibrada do Judiciário na regulação do espectro podemos mencionar que se deve dar prioridade a ações coletivas, uma vez que estas ajudam na universalização e racionalização da organização e regulação do espectro. $\mathrm{O}$ acesso direto de litigantes individuais deve ser permitido apenas em casos excepcionais, por exemplo, quando houver risco de dano irreversível ou quando do descumprimento prima facie de direitos já conferidos, contidos em lei ou programa já instituído.

Por fim, no que se refere a teorias argumentativas, há que se obedecer a regras específicas a que se deve ater a argumentação jurídica, como "preferência dos elementos normativos do sistema, o respeito às possibilidades semânticas dos textos legais, a deferência para com deliberações majoritárias válidas, a observância dos precedentes, etc. (Barroso, 2009, p. 309). Com esses cuidados, é possível pensar e aprofundar um esquema racional em que a efetivação de direitos fundamentais relacionados ao espectro radioelétrico poderiam ser efetivados por meio da atividade judicial, desde um ponto de vista neoconstitucionalista.

\section{CONCLUSÃO}

Para que o potencial dessa infraestrutura natural, que é o espectro radioelétrico, se materialize, é imperativo que as premissas do atual modelo, de sua regulação e administração, sejam vistas por outros prismas. O valor econômico e social do espectro pode aumentar, a depender da forma como se regula esse bem escasso. Hoje, a rigidez na concessão, 
uso e aplicação dos recursos de espectro se opõem ao avançado estado de convergência tecnológica em que se encontra o setor de telecomunicações.

Além disso, uma política pública efetiva de administração do espectro radioelétrico deveria ser regrada pelo princípio emancipatório da democratização das comunicações. Tal emancipação se exprime não apenas pela possibilidade de se ter acesso à informação, mas também pela realização do direito concreto à liberdade de expressão e participação. Uma democracia madura não pode prescindir dessa abertura de canais de informação.

Para que haja plenamente a objetivação desses fins, a efetividade de direitos fundamentais ligados ao espectro não pode ficar de fora. É óbvio que qualquer aplicação prática de uma constitucionalização da regulação do espectro deve orientar-se por uma teoria de ponderação equilibrada sob o risco de recair em "voluntarismos e soluções ad hoc" (Barcellos; Barroso, 2004). A racionalização da atividade judiciária nesse tema passa também pelo entendimento da natureza jurídica do espectro, de sua função social e dos pressupostos democráticos para seu uso e regulação.

\section{REFERÊNCIAS}

AMARAL, Gustavo. Saúde direito de todos, saúde direito de cada um: reflexões para a transição da práxis jurídica. In: NOBRE, Milton et al. CNJ e os desafios da efetivação do direito à saúde. Belo Horizonte: Fórum, 2011.

ARIÑO, Gaspar, et al. Las Telecomunicaciones por Cable. Su Regulación presente y futura. Madrid: Pere-Marcial Pons, 1996.

BARCELLOS, Ana Paula de. Constitucionalização das políticas públicas em matéria de direitos fundamentais: o controle político-social e o controle jurídico no espaço democrático. In: SARLET, Ingo Wolfgang; TIMM, Luciano Benetti (Orgs.). Direitos Fundamentais: orçamento e “reserva do possível”. 2. ed. Porto Alegre: Livraria do Advogado Editora, 2010. p. 101-132. 
BARCELLOS, Ana Paula; BARROSO, Luís Roberto. O começo da história. A nova interpretação constitucional e o papel dos princípios no direito brasileiro. In: SAMPAIO, José Adércio Leite (Coord.). Crise e desafios da constituição. Belo Horizonte: Del Rey, 2004.

BARROSO, Luís Roberto. A doutrina brasileira da efetividade. Temas de Direito Constitucional. Tomo III. Rio de Janeiro: Renovar, 2005. p. 61-77.

BARROSO, Luís Roberto. Curso de Direito Constitucional Contemporâneo. Rio de Janeiro: Saraiva, 2009.

BARROSO, Luís Roberto. Neoconstitucionalismo e constitucionalização do Direito. O triunfo tardio do Direito Constitucional no Brasil. In: Revista Eletrônica sobre a Reforma do Estado, Salvador, n. 9, p. 1-41, mar./abr./maio 2007.

BENJAMIN, Stuart Minor. The Logic os Scarcity: Idle Spectrum as a First Amendment Violation. 52 Duke Law Journal, 2002.

BENJAMIN, Stuart Minor et al. The Telecommunications Law ande Policy. Durnham: Carolina Academic Press, 2006.

BENKLER, Yonchai. Some Economics of Wireless Communications. $16 \mathrm{Har}$ vard Law Review, Journal of Law\& Technology, 25, 2002.

BERNAL PULIDO, Carlos. O caráter fundamental dos direitos fundamentais. Revista de Direito do Estado, 19-20:17, 2010.

BINENBOJM, Gustavo. A nova jurisdição constitucional brasileira: legitimidade democrática e instrumentos de realização. Rio de Janeiro: Renovar, 2001.

BITELLI, Marcos Alberto Sant'Anna. O direito da comunicação e da comunicação social. São Paulo: Revista dos Tribunais, 2004.

BRENTON, Philippe; PROULX, Serge. Sociologia da comunicação. São Paulo: Loyola, 1996.

CAVE, Martin et al. Essentials of Modern Spectrum Management. Cambridge: Cambridge University Press, 2007.

CRETELLA JR, José. Tratado do domínio público. Rio de Janeiro: Forense, 1984. 
DIAS, Cláudia Augusto. Hipertexto: evolução histórica e efeitos sociais. Revista Ciência da Informação, vol. 28, n. 3, Brasília, sept./dec. 1999.

FERNANDES, André de Godoy. Meios de comunicação social no Brasil: promoção do pluralismo, direito concorrencial e regulação. 2009. Tese (Doutorado) - USP, São Paulo, 2009.

GAUDEMET, Yves; CHAMINADE, André. Le Système Français D'Exploitation du Domaine Public Hertizien et DAttribuition des Fréquences Radioelétriques. 2006. Disponível em: <http://www.fondation-droitcontinental.org/upload/ docs/application/pdf/2011-10/rapport_mai_2010.pdf>.

JUSTEN FILHO, Marçal. Teoria geral das concessões de serviços públicos. São Paulo: Dialética, 2003.

KISS, A. C. The Common Heritage Principle: Utopia or Reality. International Law Review, n. 40, p. 423-442, 1985.

LEVIN, Harvey L. The Invisible Resource: Use and Regulation of the Radio Spectrum. Washington: RFF Press, 1971.

LÉVY, Pierre. As tecnologias da inteligência: o futuro do pensamento na era da informática. Rio de Janeiro: Ed. 34, 1993.

LEWIS, Michel. The New New Thing, a Silicon Valley Story. New York: W. W. Norton \& Company, 2000.

LIMA, Ruy Cirne. Princípios de Direito Administrativo. 7. ed. São Paulo: Malheiros, 2007.

LOPES, Vera Maria de Oliveira Nusdeo. O Direito à informação e as concessões de rádio e televisão. São Paulo: Revista dos Tribunais, 1997.

LOUREIRO, Luiz Gustavo. Constituição, energia e setor elétrico. Porto Alegre: Ed. Fabris Editor, 2009.

PABLO, Marcos M. Fernando. Domínio Público Radioeléctrico. In: GARCIA DE ENTERRIA; TOMAS DE LA QUADRA-SALCEDO (Org.). Comentarios a la Ley Generale de las Telecommunicaciones. Madrid: Thomson Civitas, 2004. QIANG, Christine. Information and Communication for Development. Singapura: World Bank, 2009. 
RAWLS, John. Justiça como eqüidade: uma reformulação. São Paulo: Martins Fontes, 2003.

SARMENTO, Daniel. O neoconstitucionalismo no Brasil: riscos e possibilidades. In: SARMENTO, Daniel (Coord.). Filosofia e teoria constitucional contemporânea. Rio de Janeiro: Lumen Júris, 2009.

SILVA, Aluízio Ferreira da. Direito à informação, direito à comunicação - direitos fundamentais na Constituição brasileira. 1997. Tese (Doutorado em Direito do Estado) - PUC-SP, São Paulo, 1997.

SOUZA NETO, Cláudio Pereira. A justiciabilidade dos direitos sociais: críticas e parâmetros. In: SOUZA NETO, Cláudio Pereira de; Sarmento, Daniel. (Orgs.). Direitos sociais: fundamentos, judicialização e direitos sociais em espécie. Rio de Janeiro: Lumen Júris, 2008.

STRECK, Lênio Luiz. Hermenêutica jurídica em crise. Porto Alegre: Livraria do Advogado, 2011.

SUNDFELD. Carlos Ari. O fenômeno constitucional e suas três forças. In: SOUZA Neto, Cláudio Pereira de; SARMENTO, Daniel; BINENBOJM, Gustavo (Coords.). Vinte anos da Constituição Federal. Rio de Janeiro: Lumen Júris, 2008.

WAVERMAN, Leornard. The Impact of Telecoms in Economic Growth in Developing Countries. 2011. Disponivel em: $<\mathrm{http}$ //web.si.umich.edu/tprc/ papers/2005/450/L\%20Waverman-\%20Telecoms\%20Growth\%20in\%20Dev.\%20 Countries.pdf $>$.

XAVIER, Helena de Araújo Lopes. O regime especial da concorrência no direito das telecomunicações. Rio de Janeiro: Forense, 2003.

Recebido em 14/5/2013

Aceito em 17/6/2013 